\title{
Deglaciation hydroclimatic variability in the southwest Indian Ocean
}

\author{
HANYING LI'; HAI CHENG ${ }^{12^{2 *}}$; ASHISH SINHA ${ }^{3}$, CHRISTOPH \\ SPÖTL; ; YOUFENG NING' \\ 'Xi' an Jiaotong University, Xi' an, China. \\ leehom20114@stu.xjtu.edu.cn; cheng021@xjtu.edu.cn; \\ yfning@xjtu.edu.cn \\ - University of Minnesota, Minneapolis, USA. \\ ${ }_{3}$ California State University Dominguez Hills, Carson, \\ USA.asinha@csudh.edu \\ ${ }_{4}$ Universität Innsbruck, Innsbruck, Austria. \\ christoph.spoetl@uibk.ac.at
}

Hydroclimatic variability over the tropical southwest Indian Ocean is influenced by the seasonal meridional and zonal migrations of the Inter Tropical Convergence Zone and Mascarene High respectively. In addition, the SST induced hydroclimate anomalies associated with the El Niño Southern Oscillation and (subtropical) Indian Ocean Dipole dynamics also play important roles. Hitherto, highlyresolved and chronologically precise paleoclimate records from this region are rare. In this presentation, we will present speleothem-based paleoclimate records from Rodrigues Island $\left(19^{\circ} 45^{\prime} \mathrm{S}, 63^{\circ} 23^{\prime} \mathrm{E}\right)$ that span the past 25 $\mathrm{ka}$. The paleoclimate records from this climatologically strategic location allow us to evaluate the relative importance of various dynamical processes in shaping the region's hydroclimate variability on inter-annual to suborbital timescales. A salient feature of our records is the emergence of prominent sub-millennial-scale variability during the last deglaciation period and its subsequent evolution throughout the Holocene. In this presentation, however, we will primarily discuss the dynamical nature of hydroclimate change over southwest Indian Ocean and its teleconnections to the high-latitude climate variability in southern and northern hemispheres across the deglaciation period. 